\title{
Variação e função em aférese
}

\author{
Maria Cecília Mollica \\ Universidade Federal do Rio de Janeiro - CNPq \\ Kátia Henriques do Fundo \\ CAPES \\ Luciana da Silva Gomes \\ CNPq \\ Mônica da Silva Pinto Oliveira \\ CNPq \\ Renata Flávia da Silva \\ CNPq
}

\section{Abstract}

This article focuses on the aphesis of es- with the purpose of investigating (a) why it is restricted to a very limited portion of the lexicon and (b) how a relationship between variation and function can be established regarding aphesis. The results show that such variation is controlled by principles of communicability. The more formal the speech (such as non-spontaneous narratives) the more chances of retention of es-. 


\section{AFÉRESE COMO METAPLASMO DO LATIM AO PORTUGUÊS CONTEMPORÂNEO}
A
aférese situa-se entre os fenômenos diacrônicos mais aférese se mantém como variação no Brasil no estágio atual da língua, tal como em acabar $\sim$ Øcabar. Do ponto de vista histórico, os compêndios especializados costumam arrolar o fenômeno como variação existente entre o latim clássico e o latim vulgar, estando presente também no português medieval.

$$
\begin{aligned}
& \text { Latim clássico - bebdomada > doma - português arcaico } \\
& \text { Português - aliança }>\text { liança }
\end{aligned}
$$

(cf. Williams, 1975, p.111)

No português brasileiro hodierno, as aféreses mais audiveis e/ ou mais freqüentes envolvem as cadeias a- (aqui Øqui), es- (estava $\sim$ Øtava) e en- (então Øtão). Assim, afora os inúmeros radicais que formam palavras compostas como madrepérola e embora e os possíveis prefixos que se adicionam aos radicais, quer em processos derivacionais como em anormal, quer na formação de parassíntese como em esvaziar e embelezar, há formações em que as cadeias fônicas fazem parte inerente à forma primitiva do vocábulo, portanto da raiz da palavra, como em escasso, entende e acabar, por exemplo. A possibilidade de as partículas passíveis de aférese adicionarem-se a radicais ou de estarem neles inseridos não nos permite afirmar que toda a seqüência que pode sofrer aférese seja afetada pelo processo.

Gonçalves (1992 e 1995) dedicou-se exclusiva e extensivamente à aférese de $\boldsymbol{a}$-, tanto do ponto de vista sincrônico quanto do diacrônico. Seus estudos relacionam a aférese e a prótese de $\boldsymbol{a}$ - a um 
único processo, apontando-lhes explicações de ordem estrutural e funcional. $\mathrm{O}$ autor descobriu que há uma relação intrínseca entre a variação de $\boldsymbol{a}$ - e a função desse segmento, o que permite estabelecerse uma escala de saliência mórfica segundo a qual quanto maior a função de $\boldsymbol{a}$ - menor é a chance de a aférese operar-se, e vice-versa. Assim, o $\boldsymbol{a}$ - assemântico sofre mais aférese, pois a carga semântica é baixa ou inexistente; em contrapartida, o $\boldsymbol{a}$ - mais semântico tende a reter-se com evidente e conseqüente funcionalidade. Faria et alii (1997), por sua vez, pesquisaram o processo aferético de es- e de en- em amostra de falantes analfabetos, fala dos pescadores na região Norte fluminense, com base no corpus do Projeto APERJ, do departamento de Letras Vernáculas da UFRJ, comprovando o efeito das variáveis extensão e freqüência dos vocábulos e descobrindo a função discursiva desses elementos em situação interacional.

\section{OBJETIVOS E PROCEDIMENTOS DE ANÁLISE}

Neste artigo, propomo-nos expor pesquisa realizada sobre aférese de es-, com a finalidade de responder às seguintes questões:

(a) Por que a aférese de es- acha-se circunscrita à parcela ínfima do léxico?

(b) Como se estabelece a relação entre variação/função em aférese?

Utilizamos os procedimentos da análise variacionista (cf. Labov, 1972; Scherre \& Silva, 1996), de base quantitativa, aliando-os ao exame do léxico envolvido pela aférese, conforme os ditames da Difusão Lexical (cf. Wang, 1969). Assim, foi examinado o material lingüístico, tanto por meio de correlação de variáveis (cf. VARBRUL 2S), quanto sob a perspectiva de características específicas ao vocabulário envolvido (cf. Mattos \& Mollica, 1992). Complementarmente, uma análise morfológica, semântica e socio-pragmática dos itens deu base aos aspectos funcionais do processo, de modo a atingirmos um dos nossos principais objetivos: o de estabelecer $a$ relação entre variação e função lingüística em aférese. 
O pressuposto na pesquisa é o de que a língua se insere socialmente e seu uso é permanentemente otimizado em função do grau de comunicabilidade que se deseja imprimir no discurso (cf. Macedo, mimeo. e Moura Neves, 1994). Assim, demonstramos, ao longo do trabalho, que a operação de aférese de es- é impedida em quase todos os casos, para que problemas de intercomunicação sejam evitados.

Utilizamos três tipos de amostra para atingir as metas pretendidas. Como fonte de dados de português em processo de aquisição por crianças nativas com gramática consolidada, fizemos uso da Amostra Macedo (1981); para a fase mais incipiente de aquisição, utilizamos parte da Amostra De Lemos (1974). A primeira é constituída por aprendizes entre 3 e 11 anos; a segunda é composta de duas crianças acompanhadas longitudinalmente, desde 1 ano de idade até 2 anos e 7 meses. O exame desses corpora permitiu responder a questões lançadas, embora os dados sejam comparáveis em apenas alguns aspectos. Algumas entrevistas da Amostra MOBRAL (Lemle \& Naro, 1977) foram também consultadas para dirimir dúvidas e confirmar resultados que detalhamos mais adiante.

\section{O SURGIMENTO DA VARIAÇÃO}

Desde cedo, podemos dizer que as crianças produzem aférese de es- em português, seja da maneira como os adultos a operam, seja em razão de princípios naturais ao processo de aquisição da língua. Elas apresentam aférese em formas do verbo estar, no verbo esperar e em itens como escola, estuda. No primeiro caso, a aférese é produzida categoricamente, principalmente na primeira e terceira pessoa gramatical do presente e do passado do modo indicativo - Øtá, Øtô, Øtava e na expressão pera aí. Nos nomes, os nativos em aquisição do português só operam a aférese em estágios em que possuem preferencialmente vocábulos dissílabos e padrões silábicos mais simples, como cola (cf. Ingram, 1989:372), portanto em estágios em que a gramática ainda se apresenta simplificada. 
Os resultados da análise da fala de $\mathbf{R}$ e $\mathbf{T}$, extraídos da Amostra De Lemos (1974), apontam para a hipótese do momento provável em que a aférese de es- surge e indica quais os possíveis vocábulos afetados pelo processo desde a primeira manifestação lingüística do nativo do português. Para tanto, foram ouvidas 15 entrevistas de $\mathbf{R}$ e 6 entrevistas de $\mathbf{T}$, das quais retiramos todos os itens potencial e efetivamente afetados pela aférese, para, em seguida, contabilizar os dados no intuito de saber em quantos itens houve a aplicação da regra. Vejamos as Tabelas $\mathbf{1 a}$ e $\mathbf{1 b}$, em que estão expostos os resultados referentes aos dois informantes, por idade.

\section{Tabela 1a}

\section{Índice de afetamento da aférese de es- por idade}

Amostra De Lemos: Informante $\mathbf{R}^{1}$

\begin{tabular}{|c|r|r|r|r|r|r|r|r|r|r|r|r|}
\hline Idade & $1-5-4$ & $1-6-6$ & $1-7-21$ & $1-8$ & $1-9-20$ & $1-11-3$ & $1-11-12$ & $2-0-5$ & $2-0-12$ & $2-2-19$ & $2-4-26$ & $2-7-21$ \\
\hline \multirow{2}{*}{$\mathbf{R}$} & $4 / 4=$ & $4 / 4=$ & $2 / 2=$ & $2 / 2=$ & $14 / 14=$ & $4 / 4=$ & $2 / 2=$ & $8 / 9=$ & $9 / 9=$ & $30 / 30=$ & $18 / 21=$ & $11 / 22=$ \\
& $100 \%$ & $100 \%$ & $100 \%$ & $100 \%$ & $100 \%$ & $100 \%$ & $100 \%$ & $100 \%$ & $88,8 \%$ & $100 \%$ & $85,7 \%$ & $50 \%$ \\
\hline
\end{tabular}

Tabela $1 \mathrm{~b}$

Índice de afetamento da aférese de es- por idade Amostra De Lemos: Informante T

\begin{tabular}{|c|c|c|c|c|c|c|}
\hline Idade & $1-11-14$ & $2-0-26$ & $2-1-10$ & $2-3-11$ & $2-4-18$ & $2-7-19$ \\
\hline $\mathbf{T}$ & $0 / 1=0 \%$ & $0 / 3=0 \%$ & $0 / 4=0 \%$ & $7 / 7=100 \%$ & $4 / 4=100 \%$ & $5 / 9=55,5 \%$ \\
\hline
\end{tabular}

As Tabelas $\mathbf{1 a}$ e $\mathbf{1 b}$ indicam que $\mathbf{R}$ (1a) inicia o processo de aférese desde 1 ano e 5 meses e $\mathbf{T}$ (1b) só começa a realizá-lo aos 2 anos e 3 meses. Mas as tabelas demonstram que, na idade de 2 anos e 7 meses, o índice de ocorrência de aférese é praticamente o mesmo nos dois aprendizes. 
A partir dessas considerações, reunimos as idades em dois grupos: grupo A - menos de 2 anos de idade e grupo B - mais de 2 anos. A Tabela 2 demonstra que, até dois anos, a aférese, ou não ocorre, ou ocorre em todos os ambientes nos quais se encontra a cadeia fônica es-. A partir de 2 anos, a aférese deixa de ser categórica tanto na aplicação quanto na não-aplicação da regra, quando então a variação em questão tem início. Examine-se a Tabela 2.

\section{Tabela 2}

Índice de aférese de es- por idade: $>2<$ Amostra De Lemos: Informante $\mathrm{Re} T$

\begin{tabular}{|c|c|c|}
\hline Idade & menos de 2 anos & mais de 2 anos \\
\hline $\mathbf{R}$ & $32 / 32=100 \%$ & $76 / 91=83,51 \%$ \\
\hline $\mathbf{T}$ & $0 / 1=0 \%$ & $16 / 27=59,25 \%$ \\
\hline
\end{tabular}

Cabe observar que, mediante comportamentos tão distintos de $\mathbf{R}$ e $\mathbf{T}$ (Tabelas 1a e 1b), não estamos ainda em condição de indicar o marco inicial da variação em tela, embora, pela Tabela 2, isso seja sugerido.

Após a análise dos itens lexicais nas crianças $\mathbf{R}$ e $\mathbf{T}$, constatamos que todos os casos de verbo estar foram afetados pelo processo, enquanto os do verbo esperar foram-no em parte. Outros itens como esquilo, estória e escrevi sofreram aférese de acordo com o que tradicionalmente a literatura sobre aquisição confirma. A Tabela 3 apresenta os itens com possibilidades de sofrer aférese, nos arquivos de $\mathbf{R}$ e $\mathbf{T}$, pelo número de vezes que ocorreram. 


\section{Tabela 3}

\section{Ocorrência do item}

Amostra De Lemos: Informante Re T

\begin{tabular}{|l|c|c|c|}
\hline Itens lexicais & R & T & Total \\
\hline escuro & 1 & 0 & 1 \\
\hline espelho & 1 & 0 & 1 \\
\hline escrever & 1 & 0 & 1 \\
\hline esfregar & 1 & 0 & 1 \\
\hline escola & 6 & 0 & 6 \\
\hline esquilo & 0 & 2 & 2 \\
\hline estragou & 0 & 2 & 2 \\
\hline estrelinha & 0 & 2 & 2 \\
\hline escrevi & 2 & 0 & 6 \\
\hline espera & 3 & 0 & 4 \\
\hline estória & 6 & 0 & 13 \\
\hline estava & 4 & 0 & 104 \\
\hline estou & 13 & 0 & 16 \\
\hline está & 88 & & 2 \\
\hline
\end{tabular}

Pela Tabela 3, o número de ocorrências do verbo estar é bem maior que o dos outros itens, principalmente o da forma está, que aparece 104 vezes e é responsável por quase 100\% dos casos de aférese. O item espera sofre aférese em uma das três vezes em que aparece e os demais itens ocorrem pouco.

Imaginamos então que a variação começa por volta dos 2 anos de idade e, em princípio, poderia ocorrer em qualquer item (preferencialmente nos mais freqüentes e nos estruturalmente mais simples), mas ela desaparece completamente, mantendo-se tão somente nos verbos estar e esperar. Queremos supor que, nos iniciantes, pode haver aférese (em potencial) em todas as palavras, especialmente naquelas próprias ao vocabulário das crianças: em esvaziar, a variação é bastante improvável, enquanto, em escola Øcola, é possível, pois faz parte do universo infantil. 
Inicialmente, levantamos a hipótese de que a escola teria uma influência sobre o desaparecimento paulatino da aférese em razão do contato com a escrita. No entanto, o exame de entrevistas da Amostra MOBRAL (cf. Lemle \& Naro) infirmou essa suspeita, demonstrando que a questão se explica por princípios de aquisição da linguagem: uma gramática madura, mesmo em falantes com pouca ou nenhuma escolarização, como é o caso dos informantes do MOBRAL (falantes analfabetos) só apresenta aférese nas formas do verbo estar e na expressãopera aí, tal como em falantes mais velhos escolarizados.

\section{RELAÇÃO ENTRE VARIAÇÃO E FUNÇÃO}

Assim, o fato de os demais itens do léxico deixarem de se submeter a processo de aférese merece investigação tanto curiosa quanto cuidadosa, visto que os falantes iniciam sua trajetória de forma categórica, no caso do verbo estar, por exemplo, e de forma variável em alguns outros itens. A explicação primeiramente lançada prende-se à questão da freqüência lexical. Suponhamos que a aférese nas formas do verbo estar permanecesse no estágio adulto do falante pelo fato de ocorrerem mais. Conferir, na Tabela 4, os índices percentuais de aférese por itens atingidos na Amostra Macedo que, no entanto, apresenta input da regra diferenciado mesmo entre as formas do verbo estar : cerca de $90 \%$ em estou, está, estava, em comparação a índices menores para estavam, estão, estiverem, sem falar nos casos de espera e escola. 


\section{Tabela 4 \\ Aférese de es- \\ Índice de freqüência dos itens em crianças de 3 a 11 anos \\ Amostra De Lemos: Informante $\mathrm{Re} T$}

\begin{tabular}{|l|c|c|}
\hline Item lexical & Ocorrências & Aplicação da Regra \\
\hline estou & 79 & $77 / 79=97,5 \%$ \\
\hline está & 213 & $201 / 213=94,4 \%$ \\
\hline estava & 222 & $203 / 222=91,4 \%$ \\
\hline estavam & 12 & $9 / 12=75 \%$ \\
\hline estão & 13 & $8 / 13=61,5 \%$ \\
\hline estiverem & 2 & $1 / 2=50 \%$ \\
\hline espera & 9 & $6 / 9=66,7 \%$ \\
\hline escola & $\mathbf{4 8}$ & $\mathbf{1} / \mathbf{4 8}=2,1 \%$ \\
\hline
\end{tabular}

A Tabela 4 nos indica que, mesmo considerando diferenças freqüenciais de afetamento dos itens pela aférese, a freqüência não constitui razão plausível que dê conta do fato de outros itens não serem atingidos também em falantes cuja língua já se encontra adquirida em toda sua plenitude.

É importante ressaltar que a análise de correlação de variáveis por meio do pacote VARBRUL também demonstrou que freqüência não é a explicação correta, uma vez que, na Amostra Macedo, o único substantivo existente que permanece é a palavra escola, afora as diferentes formas do verbo estar. No primeiro caso, de escola, são apenas $\mathbf{4 8}$ as ocorrências e somente $\mathbf{1}$ caso afetado pela aférese, o que nos leva a concluir que se trata de um uso "tardio", um resquício de problemas de aquisição que, uma vez sanado, o item deixa de ser afetado. Por isso, passamos a verificar o efeito de variáveis somente em formas do verbo estar. Cabe informar que a análise de correlações de variáveis controlou inicialmente inúmeros fatores, mas apenas duas mostraram-se estatisticamente relevantes. 
Constatamos que há correlação positiva entre aférese e fala espontânea, isto é, fala não planejada versus discurso não espontâneo, em que a criança pretende reproduzir cantigas de roda ou histórias infantis já conhecidas e escutadas. Controlamos então a variável grau de espontaneidade discursiva com os fatores 'fala espontânea' e 'fala não espontânea'. Paralelamente, verificamos o efeito de tempo e modo verbal sobre o comportamento do verbo estar. Além de presente, pretérito imperfeito, pretérito perfeito do indicativo, futuro e pretérito imperfeito do subjuntivo, consideramos também as formas de infinitivo.

\section{Tabela 5}

Aférese de es-

Índices de freqüência e pesos relativos da aférese de es- no verbo estar

Amostra Macedo: crianças de 3 a 11 anos

\begin{tabular}{|l|c|c|}
\hline \multicolumn{1}{|c|}{ Fatores } & \% & Peso Relativo \\
\hline Espontâneo & $475 / 599=79 \%$ & .53 \\
Não Espontâneo & $56 / 70=80 \%$ & .25 \\
\hline Nomes & $1 / 48=2 \%$ & --- \\
Infinitivo & $24 / 69=35 \%$ & 0.8 \\
Presente & $292 / 314=93 \%$ & .72 \\
Pret. Imperfeito & $212 / 234=91 \%$ & .66 \\
Fut. Subjuntivo & $1 / 2=50 \%$ & .14 \\
Pret. Perfeito & $1 / 2=50 \%$ & .14 \\
\hline
\end{tabular}

Segundo a Tabela 5, no verbo estar, o peso relativo de .53 associado a discurso espontâneo e de $\mathbf{. 2 5}$, a discurso não-espontâneo revelam que os falantes tendem a recuperar as formas-padrão, mesmo que "soem" artificiais, em narrativas recontadas, como histórias infantis e cantigas de roda. O processamento espontâneo 
da fala mostra tendência inversa, a de cancelamento de cadeias de fala com es-, que não comprometem a comunicação. ${ }^{2}$

O efeito do tempo e modo verbais é significativo sobre o processo, ainda que, em alguns casos, haja poucos dados para comprová-lo. Pela Tabela 5, a aférese tende a ser evitada no pretérito perfeito e no subjuntivo. Note-se que as ocorrências do verbo estar apresentam índice de aplicação da regra próximo a 100\%, em função das formas estiver e estiverem, por exemplo. Esses resultados nos levam a supor que as formas verbais com aférese como Øtô, Øtá, Øtava não oferecem problemas na comunicação, razão pela qual a aférese não é tão refreada. Em contrapartida, formas como Øtive, Otiver podem eventualmente oferecer confusão com o verbo ter e comprometer em alguns contextos a comunicabilidade. Um levantamento dos contextos em que os dados ocorreram sugere que a maioria dos usos não oferece problemas, como "ela Øteve aqui" e "si ela Øtivesse grávida". Mas há poucos casos como "quando Øtiver meio grosso" e "depois quando Øtiver bem vermelbo mesmo" que podem ter mais de uma interpretação, isto é, estar pode ter o sentido de $\boldsymbol{t e r}$, ainda que a diferença seja muito sutil.

A categoria de nomes associada a efeito negativo em relação ao processo se explica semelhantemente: Øcola pode eventualmente confundir-se com escola em contextos comopaguei a Øcola . O caso dos infinitivos parece prender-se a outra questão: só ocorre aférese se concomitantemente ocorrer o cancelamento da vibrante pós-vocálica /r/ em posição de final de vocábulo: ele vai ØtáØ lá não oferece problemas, mas ele vai Øtar lá é pouco provável, pois tar não existe na língua. O detalhamento desta hipótese é apresentada em seguida, onde explicamos também os casos categóricos, aqueles que nunca sofrem aférese.

Assim, as hipóteses fornecidas até o momento auxiliam-nos na busca das razões pelas quais os demais itens não são atingidos. Ao observar o léxico não atingido pela aférese, sugerimos o agrupamento dos itens em três grupos distintos, a saber: 
Grupo A - A aférese provocaria a formação de uma outra palavra já existente na língua;

Grupo B - A aférese provocaria a formação de cadeias não identificadas como possíveis pelos nativos do português;

Grupo C - A aférese desfaria o processo parassintético formador de palavras, sem o qual a derivação não se verificaria.

O quadro a seguir apresenta alguns itens dos corpora trabalhados distribuídos segundo a classificação $\mathbf{A}, \mathbf{B}$ e $\mathbf{C}$, que podem servir de pista para confirmar a hipótese de que o falante já maduro não produz aférese, seja para evitar possíveis ambigüidades, seja para não construir cadeias mal formadas. Como vimos, algumas formas do verbo estar se enquadram nesses casos, no entanto as formas do pretérito perfeito e do subjuntivo fazem parte do rol dos vocábulos do Grupo A: se a aférese se dá em estiver ou estive, por exemplo tem-se Øtiver e Øtive, que pode oferecer ambigüidade com o verbo ter, razão pela qual os pesos relativos associados às formas do verbo estar, nas construções mencionadas (cf. Tabela 5), indicam efeito negativo para o processo de aférese, na maioria desses casos.

Tal fato é reforçado quando opomos, no processamento estatístico, as estruturas do tipo A versus as demais. Vejam-se os quantitativos da Tabela 6.

Tabela 6

Aférese de es-

Índices de freqüência e pesos relativos da aférese de es- no verbo estar em relação a tempo e modo verbal Amostra Macedo

\begin{tabular}{|l|c|c|}
\hline \multicolumn{1}{|c|}{ Variáveis } & \% & Pesos Relativos \\
\hline $\begin{array}{l}\text { Pret. perfeito do indicativo e } \\
\text { formas do subjuntivo }\end{array}$ & $3 / 52=6 \%$ & .01 \\
\hline Demais formas & $528 / 617=86 \%$ & .59 \\
\hline
\end{tabular}


Os números expostos na Tabela 6 reafirmam, com maior segurança estatística, que a aférese é inibida em casos como Øtive, Øtiver e é pouco refreada em formas como Øtava, Øtá. O Quadro I, a seguir, arrola dados que reiteram esses resultados.

\section{Quadro I}

Distribuição de itens potencialmente aferéticos de essegundo a classificação $A, B$ e $C$, mas que não sofrem aférese efetivamente

Amostra Macedo e MOBRAL

\begin{tabular}{|c|c|c|c|c|c|}
\hline \multicolumn{2}{|c|}{ GRUPO A } & \multicolumn{3}{|c|}{ GRUPO B } & GRUPO C \\
\hline $\begin{array}{l}\text { escada } \\
\text { escangalha } \\
\text { escapa } \\
\text { escapar } \\
\text { escasso } \\
\text { escola } \\
\text { escolher } \\
\text { escolheria } \\
\text { escolhi } \\
\text { escolho } \\
\text { esconde } \\
\text { escorre } \\
\text { escorredor } \\
\text { escorrego } \\
\text { escorrer } \\
\text { escova } \\
\text { escovinha } \\
\text { escrava } \\
\text { escravo } \\
\text { escuro } \\
\text { esforça } \\
\text { esforçada } \\
\text { esforço } \\
\text { esmalte } \\
\text { esmola } \\
\text { espaço }\end{array}$ & $\begin{array}{l}\text { espalha } \\
\text { Espanha } \\
\text { esperto } \\
\text { espiada } \\
\text { espião } \\
\text { espiar } \\
\text { esporte } \\
\text { esposa } \\
\text { esposo } \\
\text { esquina } \\
\text { esquisito } \\
\text { esteve } \\
\text { esticar } \\
\text { estive } \\
\text { estiver } \\
\text { estiverem } \\
\text { estivesse } \\
\text { estoque } \\
\text { estouro } \\
\text { estragar } \\
\text { estudo } \\
\text { esvazio } \\
\text { exportar } \\
\text { exprimo } \\
\text { expulsar } \\
\text { extrair }\end{array}$ & $\begin{array}{l}\text { esbugalhada } \\
\text { escadinha } \\
\text { estados } \\
\text { estamos } \\
\text { estandarte } \\
\text { estão } \\
\text { estar } \\
\text { estaremos } \\
\text { estaria } \\
\text { estátua } \\
\text { estavam } \\
\text { estávamos } \\
\text { esteira } \\
\text { esteja } \\
\text { esteje } \\
\text { estômago } \\
\text { estória } \\
\text { estrangeiro } \\
\text { estranhei } \\
\text { estranho } \\
\text { estranhos } \\
\text { estrela } \\
\text { estuda } \\
\text { estudando } \\
\text { estudar } \\
\text { estudasse } \\
\text { estudava } \\
\text { estudioso } \\
\text { estudos } \\
\text { estudou }\end{array}$ & $\begin{array}{l}\text { estudou } \\
\text { estúpida } \\
\text { expediente } \\
\text { experiência } \\
\text { experimenta } \\
\text { experimentar } \\
\text { experimentei } \\
\text { explicar } \\
\text { explodido } \\
\text { explorando } \\
\text { esquece } \\
\text { esquecer } \\
\text { esqueci } \\
\text { esquecido } \\
\text { esqueço } \\
\text { esqueleto } \\
\text { esquerda } \\
\text { estabilidade } \\
\text { estacionamento } \\
\text { estado } \\
\text { esconder } \\
\text { escondia } \\
\text { escorregão } \\
\text { escreve } \\
\text { escrevendo } \\
\text { escrever } \\
\text { escrito } \\
\text { escritório } \\
\text { escudo } \\
\text { esculpir }\end{array}$ & $\begin{array}{l}\text { escuta } \\
\text { escutando } \\
\text { escutar } \\
\text { escute } \\
\text { escuto } \\
\text { escutou } \\
\text { esfrega } \\
\text { espada } \\
\text { espalhada } \\
\text { espátula } \\
\text { especialmente } \\
\text { espécie } \\
\text { espelho } \\
\text { espera } \\
\text { esperança } \\
\text { esperando } \\
\text { esperar } \\
\text { esperava } \\
\text { espero } \\
\text { espetáculo } \\
\text { espetando } \\
\text { espeto } \\
\text { espinafre } \\
\text { espírito } \\
\text { esportiva } \\
\text { espreme }\end{array}$ & $\begin{array}{l}\text { esquenta } \\
\text { esquentar } \\
\text { escaldar } \\
\text { esborrachar } \\
\text { esvaziar } \\
\text { esfaquear }\end{array}$ \\
\hline
\end{tabular}


Com base na interpretação dos resultados estatísticos das Tabelas 5 e 6 e na observação e análise das listas das palavras do Quadro I, podemos sintetizar as principais conclusões deste estudo:

(a) a aférese de es- só atinge o verbo estar, em geral, pois o item não se enquadra nos casos arrolados em (A), (B) e (C).

(b) a aférese atinge também o verbo esperar somente na expressão "pera aî", pois já houve um processo de desgramaticalização (cf. Hopper \& Traugott, 1993). Através dele, a forma verbal sofreu erosão fonética e, adicionado ao dêitico "aâ", submeteu-se a uma modificação sintático-estrutural: deixou de ter seu valor de predicação verbal, passando a constituir-se um marcador discursivo-interacional.

(c) o cancelamento de es- é refreado nas formas do verbo estar, que podem oferecer (em contextos raros) ambigüidade com o verbo ter : estive $\sim$ Øtive; estivesse $\sim$ Øtivesse.

É possível que a aférese de en- esteja sujeita a explicações semelhantes. O exame dos itens nas entrevistas nos mesmos corpora comprova que: (a) en- não pode ser cancelado em casos como embolsada ou empresta, pois constitui oposição sígnica com bolsada e presta; (b) en- não pode ser cancelado em embolsar ou embrulbar, pois bolsar e brulbar são cadeias inexistentes no português. A aférese em então e entende, no entanto, contraria esta análise, pois tão e tende são vocábulos da língua, fato que exigiria pesquisa específica sobre o assunto. ${ }^{3}$

Concluímos então que a variação da aférese é controlada por princípios de comunicabilidade. Por outro lado, demonstramos que há chances maiores de ocorrer retenção do es-, portanto de evitarse a aférese, em narrativas "pretensamente" recontadas: em narrativa não-espontânea, o falante tende a hipercorrigir, na fala, quando imagina estar próximo da modalidade escrita da língua e/ou da variante standard. 


\section{OUTRAS MOTIVAÇÕES E HIPÓTESES}

Neste artigo, procuramos estabelecer a díade variação/função em aférese com base em alguns pressupostos, embora outras explicações sejam tão plausíveis quanto desejáveis. Do Fundo (no prelo) analisa aspectos referentes a processamento de fala e a efeito de variáveis sociais distintas, tais como bens materiais e bens culturais. A pesquisa da autora investiga também o português escrito em diversos estágios, assim como o português do movimento modernista na literatura, buscando demonstrar que a aférese de esem estar foi interpretada pelos escritores como uma incorporação da escrita de uma forma saliente da fala, tal como 'né', 'pra', etc.

Podemos assegurar que não se trata de resíduo como entende Wang (1969) e como Mollica (1994) atestou para a variação 'também' 'tamém', pelo fato de apenas o processo afetar um único item. No caso da pesquisa aqui exposta, não há aleatoriedade, pois a variação é controlada. A hipótese de estar havendo discursivização da forma 'tá' como marcador apenas reforça a descoberta de que o processo de degramaticalização é possível, pois não há impedimento de natureza sistêmica ou de comunicação neste caso. As evidências mostram portanto que não é caso de final nem de início de mudança. O item afetado pela aférese o é por razões de funcionalidade na comunicação.

\section{NOTAS}

${ }^{1}$ A variável 'idade' é indicada assim no $1^{\circ}$ algarismo, o número de anos, no $2^{\circ}$ algarismo, o número de meses e, no $3^{\circ}$ algarismo, o número de dias, como nos exemplos: 1-5-4 equivale a 1 ano, 5 meses e 4 dias; $1-8$ equivale a 1 ano e 8 meses; 2-0-5 equivale a 2 anos e 5 dias.

${ }^{2}$ Não apresentamos os resultados referentes ao efeito de pessoa gramatical sobre a aférese de es- em estar, porque as crianças (pelo menos na Amostra Macedo) não usam a $1^{\underline{a}}$ pessoa do plural, preferindo a forma 'a gente', o que impede uma prova estatística real do que estamos afirmando. No entanto, nossa hipótese é a de que o uso de formas verbais em diferentes pessoas gramaticais é relevante para 
o processo de aférese de es-, o que nos leva a supor que há questões de formalidade e de funcionalidade também envolvidas na aférese. Os falantes operam o processo especialmente na $1^{\underline{a}}$ e $3^{\underline{a}}$ pessoas do singular; quase não o fazem na $3^{\underline{a}}$ pessoa do plural e jamais realizam-no na $1^{\underline{a}}$ pessoa do plural.

De fato, a ocorrência da forma 'nós Øtamos' só seria "natural" na fala, se acompanhada do cancelamento do -s como em 'nós ØtamoØ'. O falante com perfil para produzir sintagma desse tipo preferiria 'a gente $\varnothing \mathbf{t a m o} \boldsymbol{\varnothing}$ ', cuja principal razão liga-se ao baixo índice de escolaridade, provavelmente. A escolha da $1^{\mathrm{a}}$ pessoa do plural nós já pressupõe maior formalidade de fala. Assim, as formas mais preferidas, portanto mais freqüentes em discurso espontâneo, são a $1^{\underline{a}}$ e $3^{\underline{a}}$ pessoas do singular, nas quais as chances da aférese são natural e conseqüentemente maiores.

Ainda que as crianças da Amostra Macedo não apresentem o uso da $1^{a}$ pessoa do plural, os falantes adultos da Amostra Censo utilizam a $1^{\underline{a}}$ pessoa do plural com significativa operação da aférese (cf. Do Fundo, 1998) a depender do perfil do falante. Por exemplo, os analfabetos do MOBRAL chegam a um índice de 80\% de aférese na $1^{\text {a }}$ pessoa do plural: de 5 ocorrências da forma, 4 são de tamo. Esta parece uma evidência indireta de que o grau de formalidade mantém estreita relação com o fenômeno. Se isso se confirma, estamos evidenciando que o falante parece atento, também no caso da aférese, ao contexto pragmático em que se dá o evento de fala, de modo a adequar-se lingüisticamente.

${ }^{3}$ Não submetemos os dados de en- a análise varbruliana tal como fizemos para es-, uma vez que o input da regra é muito baixo. Por outro lado, gostaríamos de salientar que a aférese em então produz a forma tão, advérbio de intensidade. Achamos, porém, que praticamente inexistem contextos em que advérbio e verbo sejam permutáveis e tragam problemas de comunicação, fato que complica ainda mais uma pesquisa específica sofre a aférese de en-, comparada à que estamos procedendo para a aférese de es-.

\section{REFERÊNCIAS BIBLIOGRÁFICAS}

DE LEMOS, C. Amostra de fala de crianças. Campinas: UNICAMP, 1974.

DO FUNDO, K. H. Oprocesso de aférese dees-. Dissertação de Mestrado. Faculdade de Letras, UFRJ, no prelo.

FARIA, C. V. S. et alii. Aférese dos segmentos es- e en- na fala dos pescadores do norte do Estado do Rio de Janeiro. Monografia de Doutorado, UFRJ, 1997.

GONÇALVES, Carlos Alexandre V. Aférese e prótese: verso e reverso fonológico. IN: Revista de Estudos da Linguagem. Belo Horizonte, Faculdade de Letras, UFMG, 1992, ano 1, no 1 , p. 65-77. 
GONÇALVES, Carlos Alexandre V. Aférese e prótese: verso e reverso morfológico. Dissertação de Mestrado, UFRJ, 1995.

HOPPER, P. J. \& TRAUGOTT, E. C. Grammaticalization. Cambridge University Press, 1993.

ILARI, Rodolfo. Lingüistica Românica. São Paulo: Ática, 1992.

INGRAM, D. First language acquisition: metbod, description and explanation. Cambridge University Press, 1989.

LABOV, W. Sociolingüistic patterns. Philadelphia: University of Pennsylvania Press, 1972.

LEMLE, M. \& NARO, A. J. Competência básica do português. Rio de Janeiro: MOBRAL, Fundação FORD, 1977.

MACEDO, A.T. (org.) Amostra de fala de crianças. PEUL, UFRJ, 1983. (Mimeo.). . Funcionalismos. UFRJ, (Mimeo.).

MOLliCA, M. C. \& MATTOS, P. Pela conjugação das abordagens variacionista e difusicionista. In: Revista de Estudos da Linguagem. Belo Horizonte, Faculdade de Letras, UFMG, 1992, ano 1, nº 1, p.53-63.

. Um caso de resíduo no português atual. IN: D.E.L.T.A., São Paulo, vol.10, n⿳⺈ 1, 1994, p. 1-6.

MOURA NEVES, M.H. Uma visão geral da gramática funcional. In: ALFA - Revista de Lingüística. UNESP, São Paulo, vol. 38, 1994, p. 109-127.

SCHERRE, M. M. \& SILVA, G. M. O. (Orgs.). Padrões sociolingúísticos. Rio de Janeiro: Tempo Brasileiro, 1996.

WANG, W.S.Y. Competing changes as cause of residue. Language, vol. 45, n⿳丷ㅜ 1 , março, 1969, p. 9-25.

WILliams, E. B. Do latim ao português. 3.ed. Rio de Janeiro: Tempo Brasileiro, 1975. 